\title{
sciendo
}

\section{PATIENT CARE APPROACH USING NURSING THEORIES - COMPARATIVE ANALYSIS OF OREM'S SELF-CARE DEFICIT THEORY AND HENDERSON'S MODEL}

\author{
LAURA GLIGOR ${ }^{1}$, CARMEN DANIELA DOMNARIU ${ }^{2}$ \\ ${ }^{1}$ PhD candidate "Lucian Blaga” University of Sibiu, ${ }^{2}$ "Lucian Blaga” University of Sibiu
}

\begin{abstract}
Keywords: $\quad$ nursing Abstract: Nursing theories have been developed to provide guidance in clinical practice, so their theories, Henderson's knowledge by nurses is mandatory in order to provide advanced nursing care. This paper presents the model, Orem's self-care relationships between the concepts and major assumptions of Henderson's model and Orem's theory deficit theory, nursing and then their comparative analysis. Both, Henderson's model and Orem's theory of self-care deficit practice have a major impact, internationally, in education and research, but also in nursing practice, as a result of which their knowledge can open a new perspective on care, especially in countries where they are not well enough known.
\end{abstract}

\section{INTRODUCTION}

Changes in health in recent years in terms of technology, skills and professional knowledge, needs and expectations of patients have led to a dynamic health system. The increase in life expectancy and chronic diseases, the development of day surgery, the increase in primary care and a continuous reduction in hospitalization have all contributed to the changing patterns of need and demand in the system.(1) In particular, these changes lead to the development of new methods of patient care and the change in the professional roles of nurses.(2)

In the new context, it will not be enough to use the biomedical model as a conceptual framework to guide nursing practice. Reviewing existing nursing theories, testing their relevance in current nursing practice can be viable solutions in a dynamic medical system.(3)

It is generally accepted that nursing theories establish the structure and organization of nursing knowledge and ensure a systematic collection of data to describe, explain and anticipate nursing practice. The use of theory promotes a rational and systematic practice. They make the practice of nursing focused not only on the practice itself but also on specific objectives. Theories also clarify nursing as a discipline and its purpose.

A distinction is made between nursing and other disciplines that provide patient care by establishing professional boundaries.(4) Nursing cannot be considered a profession if there is no theoretical basis for practice. Nursing theories are an important part in the development of the discipline forming the basis of theoretical knowledge necessary for practice.(5)

The practice of nursing is complex, but without the use of theory it becomes a mechanical practice, based on tradition, intuition and the execution of tasks.(6) Although the development and study of nursing theories began decades ago, it has been observed that nurses rarely use them in clinical practice. Moreover, they are found in institutions that have special policies in this regard or those that are subject to the accreditation process. $(7,8)$

\section{AIM}

The aim of this article is to present the relationships between the assumptions and concepts of Virginia Henderson's model and Orem's self-care deficit theory (SCDNT). Then, the two are compared in terms of similarities and differences related to the philosophical underpinnings of the theory, the relationship with the nursing metaparadigm, utility and testability, parsimony and their value in the development of the discipline.

\section{MATERIALS AND METHODS}

There were studied articles from international databases (PubMed, CINAHL, Nursing \& Allied Health Database) and books from the last 10 years.

There were also considered older books that are relevant to the subject.

The choice of theories was made taking into account the degree of testing and verification of them through research. On this principle, Orem's theory of self-care deficit was selected, being considered a defining nursing theory at the international level.

The context of providing care in Romania, but also in other Central and Eastern European countries led to the introduction of Virginia Henderson's model in the study.

Currently, in Romania, Virginia Henderson's model is the only one studied in detail in nurses' training programmes.

For this reason, it has been introduced in clinical practice in many of the health units in Romania.

In this study, there were considered the analysis criteria used by McEwen, which are similar to those described by Fawcett and DeSanto-Madeya.(9) These criteria were also promoted by Walker and Avant (10) in the analysis and evaluation of nursing theories.

They include seven criteria and provide a descriptive rather than analytical or evaluative understanding of theories. The criteria are the following: philosophical underpinnings of the theory; major assumptions, concepts and relationships; utility; testability; parsimony; value in expanding nursing science. (5)

${ }^{1}$ Corresponding author: Laura Gligor, Aleea Seviş, Nr. 14, B1. Y2, Sibiu, România, E-mail: lauraburchea@yahoo.com, Phone: +40740 310753. Article received on 08.04.2020 and accepted for publication on 28.05.2020 

assumptions

Relationships between concepts and major

Orem's Self-Care Deficit Theory (SCDNT)

Orem's theory has been modified over time to fit the concept of the individual and the nursing system. However, the original theory remained almost untouched. SCDNT is presented as a general nursing theory that encompasses three theories. The three "nest" theories delimited by Orem are the following: the theory of self-care, the deficit of self-care and the nursing system. $(5,11)$

Nursing system theory includes the theory of self-care deficit, and explains the relationships needed to streamline the care process.(12) Orem suggests that the nursing system is determined by the patient's limitations in care. Therefore, the type of care provided varies within the system. Thus, the nurse can provide total care (critically ill patients), partial care (patients in rehabilitation) and educational and supportive care (patient education).(7)

Self-care theory is a component of SCDNT that describes why and how people care for themselves. Self-care is learned and must be performed deliberately and consciously over time and according to the needs of the individual.

The theory of self-care deficit explains and describes why people can be helped through nursing. The term self-care deficit expresses the relationship between the individual's capacity for action and his or her care needs.(12)

Orem adds a fourth theory, the theory of dependent care, which was initially introduced as a corollary to the theory of self-care. The theory explains how family members and/or friends provide care to the socially dependent person. The conceptual elements of the theory and the relationships between them are still in development and definition.(13)

A basic premise of Orem's theory is that human beings are concerned with the continuous communication between them and the constant exchange with the environment for living. Individuals have the ability to act deliberately and this is demonstrated by identifying needs and making decisions by them. Human intervention is present in the discovery, development and transmission to others of ways to identify needs for both themselves and others. Moreover, groups of individuals with a structured relationship establish tasks and responsibilities to provide care to other groups that have deficiencies in making deliberate decisions for themselves and others.(14)

Orem formulated several major concepts in his theory and a marginal concept. The marginal concept is represented by the basic conditional factors (age, sex, health etc.). Six of the major concepts are essential to understanding Orem's theory as follows: self-care, self-care agency, therapeutic self-care demand, self-care deficit, nursing agency, nursing system.(15)

\section{Virginia Henderson's model of care}

Virginia Henderson's concept of nursing comes from her education and experience, so her theory is inductive.

The major assumption of the model is that the nurse takes care of the patient until he can take care of himself again. Henderson assumes that the patient wants to gain health, but this is not clearly expressed in theory. It also assumes that the nurse is devoted to the patient throughout this period. Educating nurses at the university level in the spirit of art and science is Henderson's final assumption. $(5,16)$ She believes that the nurse's sole role is to help the person, sick or healthy, to perform those activities that contribute to maintaining health or recovery.

Based on her definition of nursing and the term "basic nursing care", Henderson identified 14 components of basic nursing care that address hygiene and healthy living needs. It also includes helping the patient by applying the treatment plan indicated by the doctor.(16)

The 14 fundamental components are the following: breathe normally; eat and drink adequately; eliminate body wastes; move and maintain desirable postures; sleep and rest; select suitable clothes-dress and undress; maintain body temperature within normal range by adjusting clothing and modifying environment; keep the body clean and well-groomed and protect the integument; avoid dangers in the environment and avoid injuring others; communicate with others in expressing emotions, needs, fears, or opinions; worship according to one's faith; work in such a way that there is a sense of accomplishment; play or participate in various forms of recreation; learn, discover, or satisfy the curiosity that leads to normal development and health and use the available health facilities. $(5,17)$

The first nine are physiological components, the tenth and fourteenth are related to communication and learning, the eleventh are related to the spiritual and moral component, and the twelfth and thirteenth are related to the sociological aspects of occupation and recreation.(18)

Comparative analysis of model Henderson's model and Orem's theory

Philosophical underpinnings of the theory

Orem argued that no theorist was the basis for the theory of self-care deficit. She has expressed interest in several theorists, but most often refers to Parson's theory of the Structure of Social Action and Bertalanfy's Systems Theory.(12) Therefore, his theory is an inductive one, although deductive components have been identified that have helped to clarify it.(19)

Compared to Orem, Henderson identified starting points for his nursing model. Henderson believes that her ideas were influenced by the American psychologist Thorndike, but that the theoretical ideas developed and matured due to the experience gained.(16)

\section{Relationship to the nursing metaparadigm}

The major concepts of Henderson's model are related to the nursing metaparadigm (person, health, environment, nursing), although not all are clearly defined.(5) Henderson defines "person" as someone who needs nursing care but is not limited to disease-related care. "Health" is not explicitly presented but refers to maintaining a balance at all levels of the human being. "The environment" is not clearly defined, but maintaining a supportive environment is one of the 14 components described in its model. The last concept of the metaparadigm, "nursing", although no clear definition is given, involves the nurse who cares for the patient to gain independence through the 14 components described.(16)

Orem refers to each concept of the nursing metaparadigm. "Nursing" is seen as an art through which the nurse provides specialized care to people with disabilities doing more than the necessary current care. The nurse actively participates in the medical care that the patient receives from the doctor. "Person" is defined as "men, women and children cared for either individually or as a group" and is the "material object" of the nurse and other caregivers. The "environment" has physical, chemical and biological characteristics. It includes family culture and community. "Health" is a condition that includes both individual and group health. Health is the ability to reflect on one's own health, to represent experience and to communicate with others.(12)

\section{Utility}

In clinical practice, Orem's theory is the basis for organizing care in several specialties such as community care, intensive care, obstetrics and neonatology, medical and surgical specialties, pediatrics, dialysis services. Also, certain medical 


\section{PUBLIC HEALTH AND MANAGEMENT}

conditions such as arthritis, gastrointestinal and kidney diseases have structured the care of patients using this theory.(13) The theory presents international interest and is used in countries such as the United Kingdom, Germany, Japan, the Netherlands, Norway, Sweden and New Zealand.(5) The Henderson model is used as a conceptual framework internationally. For example, Scott, Matthews, and Kirwan found that the Henderson model is the most widely used clinical practice internationally in assessing patient needs.(20)

In education, many universities and colleges in the United States of America have compiled their curricula based on Orem's theory of self-care deficit, including Illinois Wesleyan University, University of Tennessee at Chattanooga, Anderson College and University of Toledo.(5)

The principles of Henderson's model were published from the $1930 \mathrm{~s}$ to the $1960 \mathrm{~s}$, and these principles represented by the 14 fundamental concepts are still important in the evaluation of nursing care in the 21 st century.(21)

In some Central and Eastern European countries such as Slovenia and Romania, the curriculum is based on the Henderson model. In Russia and Poland, in addition to the Henderson model, Nightingale's theory, Orem's theory and Roy's model were introduced in the curriculum.(3)

In the research, Henderson's established care components were used by a team of researchers from Japan, the Netherlands, Poland and Turkey to create the scale of care dependency by measuring basic human needs.(22)

Testability

Several research studies have used Orem's theory as a conceptual framework or as a source for testable hypotheses. Also, over the years, elements of the theory have been tested in research studies. Many researches related to the theory of selfcare deficit are descriptive researches, the theory has not been fully researched.(13)

Much of the research that preceded the publication of the Henderson model has focused on the educational process and nursing as a profession. Henderson intended his model to be applicable in clinical practice so that each of the 14 components of his model are testable in practice and can also be a basis for research. $(5,21)$

\section{Parsimony}

Orem's theory is complex, comprising four theories included in each other in the form of a "nest", and having formulated several assumptions and sentences for each theory.

Revisions of the theory from the original (1971) improved its organization. However, its complexity has increased throughout each edition published in response to the needs of society.

Virginia Henderson's model is small in presentation, but complex in its purpose.

The 14 components cover the entire nursing practice and her vision of the role of the nurse in patient care contributes to the complexity of the theory. $(5,7)$

\section{Value in expanding nursing science}

In the theory of self-care deficit, the purpose of nursing is differentiated from other disciplines. Orem presented a vision of nursing education and practice expressed through a general theory.(11) It has also been used in practical cases and research projects, doctoral theses or dissertations.

The practical applicability of the theory is attractive to nursing graduates because it is perceived as a realistic reflection of nursing practice.(5)

Historically, Henderson's concept has enriched nursing as a science with major influence in education. His work has had an impact in international research by focusing on nursing practice and confirming the value of tested nursing interventions in helping the patient to regain health.(7)
DISCUSSIONS

Both Orem and Henderson were educated in the empirical period of medicine and nursing that focused on the needs of the patient.(5)

The concepts of the metaparadigm are more clearly defined by Orem compared to Henderson. Although the Henderson model follows the four concepts of the metaparadigm, the only clearly defined concept is "person", the other three are deduced. Orem vaguely defines "environment". The author makes considerable efforts to define the concept of "nursing". The "person" is seen by both authors as a beneficiary of nursing care, being in a continuous effort to survive. The approach to the concept of "health" varies significantly in the two papers.

Both works are widely recognized internationally in both education and research but especially in practice. Orem's theory is considered more useful in clinical practice than in research.(19) On the other hand, Henderson's model has profoundly influenced nursing education through Henderson's clear vision of the role of the nurse.(21)

The gradual development of Orem's theory of selfcare deficit and the low degree of complexity of Henderson's model make them more accessible for application in clinical practice.

Compared to Orem, Henderson played an important role in the development of the discipline more by elaborating the definition of the discipline and a school curriculum organized on the patient's problems than by the elaborated model. Orem has developed a theory that has broadened the horizon of research in nursing through the complexity of the approach, updating the theory over time to meet the current needs of society and originality. $(5,7)$

Both Orem's theory and Henderson's model provide nurses with a perspective to understand the patient's situation and a way to organize information into the patient daily care. They allow nurses to focus on the most important information by separating it from the irrelevant ones.

\section{CONCLUSIONS}

Both theories bring uniqueness and value to the discipline and have applicability in clinical practice. These could be a good example to use especially in countries where care is still organized according to the biomedical model. However, in order to select a nursing theory or model that meets the needs of the type of institution that provides care, it is necessary to know the selection criteria for their practical use. Therefore, studying other nursing theories besides those based on the patient's needs, two of which have been analyzed in this article, will improve the nurse's vision of the discipline and may open new horizons in addressing care.

To conclude, the knowledge of nursing theories benefits not only to nursing as a discipline, but also allows the selection of that theory that best suits a particular situation resulting in individualized care for each patient

\section{REFERENCE}

1. Williamson S, Twelvetree T, Thompson J, Beaver K. An ethnographic study exploring the role of ward-based Advanced Nurse Practitioners in an acute medical setting. J Adv Nurs [Internet]. 2012 [cited 2020 Feb 2]; 68(7):[1579. 88 pp.]. Available from: https://www.ncbi.nlm.nih.gov/pubmed/22381131

2. Lowe G, Plummer V, O'Brien AP, Boyd L. Time to clarify - the value of advanced practice nursing roles in healthcare. J Adv Nurs [Internet]. 2012 [cited 2020 Feb 10]; 68(3):[677-85 pp.]. Available from: https://www.ncbi.nlm.nih.gov/pubmed/21790738. 
3. McKenna H, Pajnkihar M, Murphy FA. Nursing models, theories and practice. 2nd ed. Atrium: John Wiley \& Sons, Ltd.; 2014.

4. Chinn P, Kramer MK. Integrated theory and knowledge development in nursing. 8th ed. St. Louis: Elsevier/Mosby; 2011.

5. McEwen M, Wills EM. Theoretical basis for nursing. 5th ed. Philadelphia: Lippincott Wiliams \&Wilkins; 2019.

6. Risjord M. Nursing knowledge: Science, practice, and Philosophy. Oxford: Wiley-Blackwell; 2010.

7. Smith M, Parker ME. Nursing theories and nursing practice. 4th ed. Philadelphia: F.A. Davis Company; 2015.

8. Liaschenko J, Fisher A. Theorizing the knowledge that nurses use in the conduct of their work. Sch Inq Nurs Pract [Internet]. 1999 [cited 2020 Ian 16]; 13(1):[29-41 pp.] Available from: https://www.ncbi.nlm.nih.gov/pubmed/10420795.

9. Fawcett J D-MS. Contemporary nursing knowledge: analysis and evaluation of nursing models and theories. 3rd ed. Philadelphia: F.A. Davis; 2013.

10. Walker L, Avant KC. Strategy for theory construction in nursing. 5th ed. Upper Saddle River: NJ: Prentice Hall; 2011.

11. Alligood M. Nursing theorists and their work. 9th ed. St Louis: Elsevier Inc.; 2018.

12. Orem D. Nursing: concepts of practice. 6th ed. St. Louis Mosby; 2001.

13. Taylor S, Renpenning K. Self-care science, nursing theory and evidence based practice. New York Springer Publishing Company; 2011.

14. Orem D. Nursing: concepts of practice. 5th ed. St. Louis: Mosby; 1995.

15. Zaccangini M, Pechacek JM. The doctor of nursing practice essentials 4th ed. Burlington Jones \& Bartlett Learing; 2020.

16. Henderson V. The nature of nursing: reflections after 25 years. New York: National League for Nursing Press; 1991.

17. Henderson V. Basic principle of nursing care. In: Smith M, Parker ME, editor. Nursing theories and nursing practice. Philadelphia: F.A. Davis Company; 2015. p. 56.

18. Baghiu V. Teoria și practica nursing: procesul de îngrijire al pacientului. București: Cartea Medicală; 2019.

19. Comely A. A comparative analysis of Orem's self care model and Peplau's theory. J Adv Nurs [Internet]. 1994 [cited 2020 Martie 1]; 20:[755-60 pp.]. Available from: https://doi.org/10.1046/j.1365-2648.1994.20040755.x.

20. Scott $P$, Matthews A, Kirwan M. What is nursing in the 21 st century and what does the 21 st century health system require of nursing. In: McEwen M, Wills EM., editor. Theoretical basis for nursing. Philadelphia: Lippincott Wiliams \&Wilkins; 2019. p. 146-7.

21. O'Malley J. A nursing legacy: Virginia Henderson. Adv Pract Nurs Q [Internet]. 1996 [cited 2020 Feb 28]; 2(2):[vvii pp.]. Available from: https://www.unboundmedicine.com/medline/citation/94470 64/.

22. D'ijkstra A, Yont GH, Korhan EA, Muszalik M, KedzioraKornatowska K, Suzuki M. The care dependency scale for measuring basic human need: an international comparison. In: Alligood M, editor. Nursing theorists and their work. St. Louis: Elsevier Inc.; 2018. p. 14-6. 